Erratum

\title{
Production ecology of the non-indigenous seagrass, dwarf eelgrass (Zostera japonica Ascher. \& Graeb.), in a Pacific Northwest Estuary, USA
}

\section{James E. Kaldy}

Western Ecology Division, US Environmental Protection Agency, 2111 SE Marine Science Center Dr., Newport, OR 97365, USA

Tel.: + 1 541-867-4026, E-mail: Kaldy.jim@epa.gov

There was an error in my paper published in Hydrobiologia (Vol. 553, p. 201-217, 2006). An error in a spreadsheet formula resulted in an underestimate of leaf elongation rates for Zostera japonica shown in Figure 7. The corrected leaf elongation rates are shown here. Additionally, the first sentence of the last paragraph on page 210 should read "Leaf elongation rates ranged between ca. $0.16 \mathrm{~cm} \mathrm{sht}^{-1} \mathrm{~d}^{-1}$ during February 2002 and $0.79 \mathrm{~cm} \mathrm{sht}^{-1} \mathrm{~d}^{-1}$ during April 2002 (Fig. 7)."

I thank Deborah Shafer (US Army Corps of Engineers, Engineer Research and Development Center, Vicksburg, MS) for identifying this error.

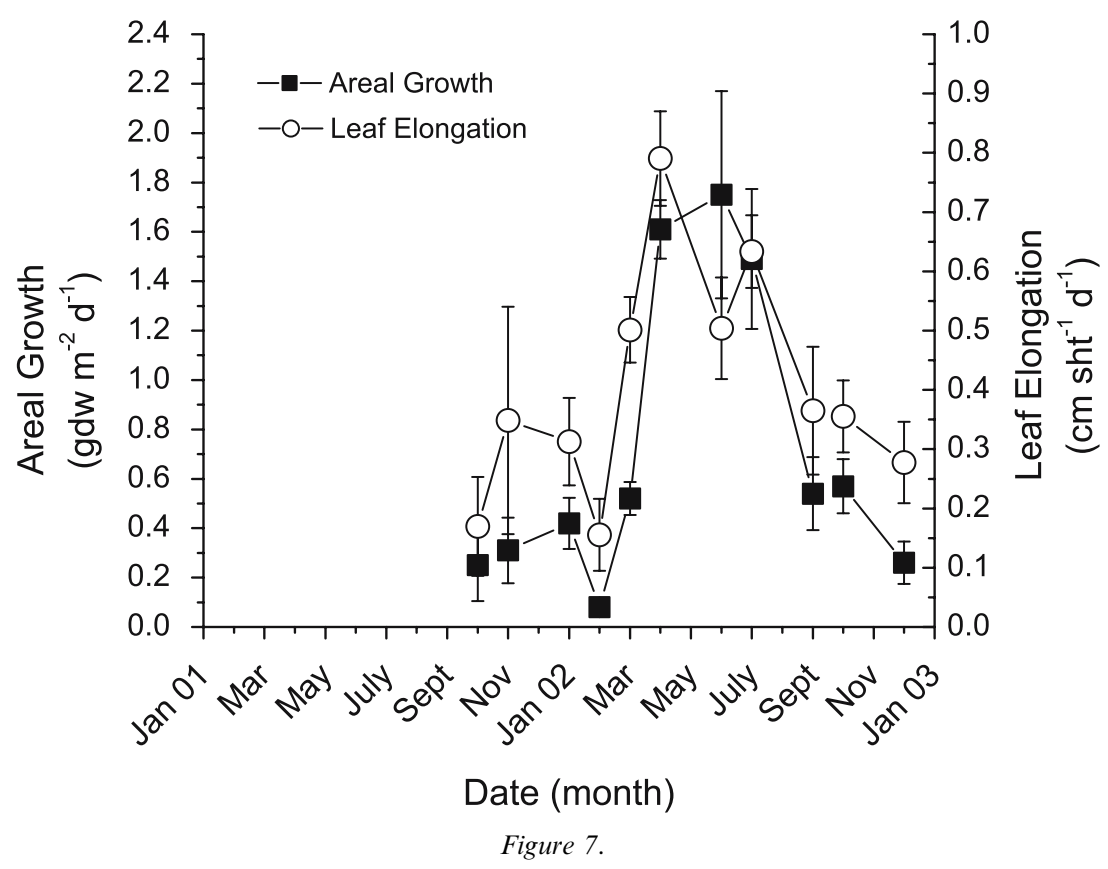

